\title{
ANALISIS VULNERABLE PORT PADA CLIENT PENGGUNA PUBLIK WIFI
}

\author{
Jemi Yohanis Babys \\ Program Studi Teknik Informatika \\ STIMIK Kupang \\ Email: betajemz@gmail.com
}

\begin{abstract}
ABSTRAK
Penggunaan publik wifi sangat rentan terhadap attacker. Salah satu cara yang dapat dimanfaatkan oleh attacker untuk melakukan eksploitasi dan menyebarkan malware pada jaringan publik wifi adalah dengan cara memanfaatkan vulnerable port pada client. Untuk mengatasi hal ini, maka dalam penelitian ini dilakukan pengujian keamanan port pada client yang menggunakan publik wifi. Tahapan dalam penelitian ini adalah: 1) Information gathering, fungsinya untuk mengetahui target client, port yang terbuka dan services yang berjalan. 2) Finding vulnerability, berdasarkan information gathering, dilakukan identifikasi untuk mengetahui potential vulnerability pada client. 3) Exploiting vulnerabilities, melakukan exploitation terhadap vulnerability yang ditemukan. 4) Recommendation, bertujuan untuk memberikan solusi berupa saran untuk mengamankan vulnerability yang ditemukan. Hasil dari penelitian ini menunjukan bahwa terdapatnya open port pada pengguna public wifi berpotensi menyebabkan pengguna dieksploitasi oleh attacker. Berdasarkan penelitian yang dilakukan, diketahui bahwa, beberapa user tidak peduli dengan keamanan informasi, terutama mengenai pentingnya melakukan update pada aplikasi maupun update pada sistem operasi yang digunakan, dan juga pengguna masih kurang sadar mengenai pentingnya keamanan open port yang dapat berpengaruh terhadap keamanan informasi.
\end{abstract}

Kata kunci: vulnerability, vulnerable port, publik wifi.

\section{ABSTRACT}

The use of public wifi is particularly vulnerable to attackers. One of many ways that attackers can be use to exploit and spread malware on public wifi is by exploiting vulnerable ports on the client. To solve this problem, in this research the researcher will test the security port on the public wifi client. Here are the steps of this research: 1) Information gathering, this stage to find out the target client, open port and running services. 2) Finding vulnerability, based on information gathering, researchers will perform identification to determine potential vulnerability in client. 3) Exploiting vulnerabilities, function of this step is to exploit vulnerability were found in client. 4) Recommendation, aims to provide solutions like advice to secure the vulnerability were found. The results of this study indicate that the presence of open ports on public wifi users has the potential to cause users to be exploited by the attacker. Based on the research, it is known that, some users do not care about the security of information, especially regarding the importance of updating the applications and updating the operating system, and also users are still less aware of the importance of open port security that can affect the security of information.

Keywords: vulnerability, port, public wifi.

\section{PENDAHULUAN}

Seiring dengan pesatnya perkembangan teknologi jaringan komputer dan internet saat ini, berkembang juga ancaman terhadap keamanan jaringan. Oleh karena itu, keamanan jaringan harus menjadi perhatian utama dalam membangun jaringan untuk menjamin keamanan informasi digital yang berada di dalamnya [4].

Menurut data yang diperoleh dari The European Union Agency for Network and Information Security (ENISA) salah satu masalah keamanan jaringan yang terjadi pada bulan Mei 2017 adalah munculnya crypto-ransomware yang sering disebut WannaCry / WannaCrypt / WanaCryptOr / WCrypt / WCRY yang menyerang berbagai organisasi dan perusahaan. WannaCry menyebar dengan memanfaatkan vulnerability pada port 445. Port 445 merupakan port yang digunakan oleh SMB (Server Message Block). SMB merupakan protokol pada Microsoft Windows yang digunakan untuk melakukan file-sharing antar client dalam jaringan. Berdasarkan data dari ENISA tersebut diketahui bahwa WannaCry menyebar dengan memanfaatkan vulnerability pada sistem operasi Windows [6].

Serangan yang memanfaatkan vulnerable port seperti WannaCry bisa saja terjadi lagi, terutama pada jaringan publik seperti publik wifi yang sering dijumpai di cafe, restoran, hotel maupun airport. Jaringan ini penuh dengan resiko keamanan yang tentunya akan mengancam informasi yang terdapat didalamnya [4]. 
Oleh karena itu, dalam penelitian ini akan menganalisis vulnerable port pada client yang menggunakan jaringan publik wifi untuk mencegah terjadinya eksploitasi dan penyebaran malware melalui vulnerable port.

\section{METODOLOGI PENELITIAN}

Metode pengumpulan data dalam penelitian ini adalah sebagai berikut:

\subsection{Studi Kepustakaan}

Metode studi kepustakaan dilakukan dengan mempelajari literatur-literatur terkait yang berhubungan dengan penelitian untuk digunakan sebagai acuan.

\subsection{Observasi}

Pada metode observasi ini akan dilakukan pengamatan secara langsung pada jaringan publik wifi. Dalam penelitian ini observasi dilakukan pada jaringan wifi di kampus STIMIK Kupang, karena jaringan wifi ini cukup untuk mewakili jaringan publik wifi yang ada di Kota Kupang.

\subsection{Eksploitasi}

Dalam penelitian ini eksploitasi digunakan untuk mengetahui vulnerable port pada client. Eksploitasi dilakukan menggunakan Kali Linux Operating System, Zenmap, Nmap, dan Metasploit Framework. Tahapan dalam melakukan eksploitasi dapat dilihat pada gambar 1.

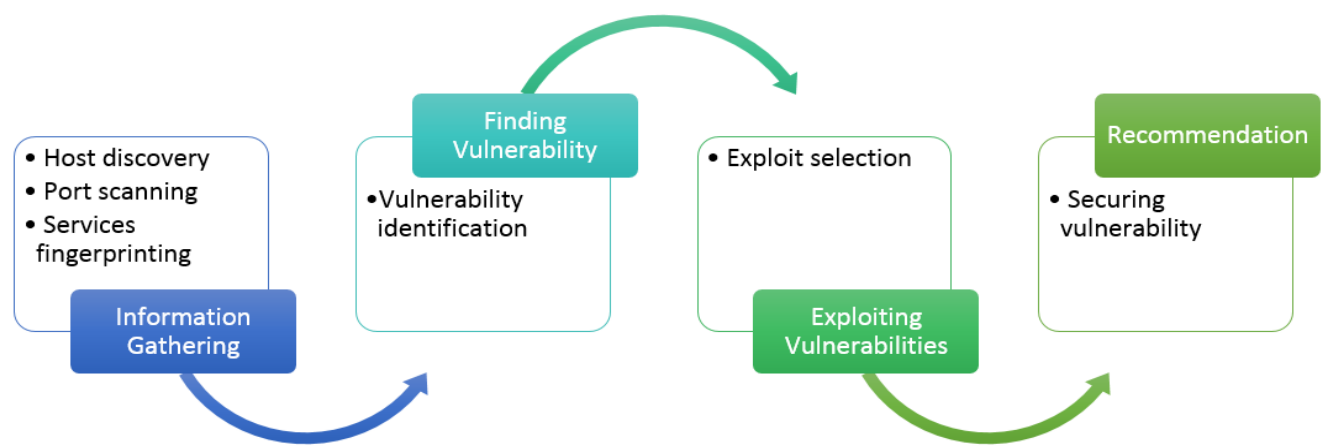

Gambar 1. Tahapan Eksploitasi [8]

\subsubsection{Information Gathering}

Tahap awal dalam proses pengujian yaitu pengumpulan informasi, informasi yang dikumpulkan berupa host (client) target yang akan dianalisis, status port, dan services yang berjalan.

\subsubsection{Finding Vulnerability}

Tahap ini mencari dan mempelajari potential vulnerability dari services yang berjalan pada komputer target.

\subsubsection{Exploiting Vulnerability}

Tahap exploiting vulnerability merupakan upaya menguji vulnerability yang ditemukan.

\subsubsection{Recommendation}

Recommendation merupakan tahap memberikan solusi berupa saran untuk mengamankan setiap vulnerability yang ditemukan.

Terdapat beberapa penelitian yang menunjukan resiko dari vulnerable port diantaranya Navamani, B.A., Yue, C. dan Zhou, X dalam penelitian berjudul An Analysis of Open Ports and Port Pairs in EC2 Instances, penelitian ini melakukan analisis untuk menunjukan resiko status open port pada cloud environment. Analisis dilakukan di virtual machine (VM) instances Amazone Web Services (AWS) dengan menggunakan software pemindai jaringan Zmap yang telah di costumized. Proses pemindai 
jaringan menargetkan single port pada multiple server. Penelitian ini menyoroti bagaimana penyerang dapat melakukan serangan yang tidak terdeteksi dengan mengkombinasikan 2 karakteristik port yang berbeda didalam sebuah VM instance. Selain itu, dipaparkan beberapa cara untuk melindungi port dari serangan [3].

Lee, et. al. dalam penelitiannya mengenai Implementation and Vulnerability Test of Stealth Port Scanning Attacks using ZMap of Censys Engine. Dalam penelitian ini dilakukan proses sthealt port scanning menggunakan Zmap di Universitas Ajou. Proses scanning dilakukan di dari 12.000 hosts pada 2 range IP address. Port yang di scan adalah port 23 (telnet), 25 (smtp), 80 (http), 443 (https), 525 (printer) dan port 25565 (game minecraft). Berdasarkan hasil penelitian yang dilakukan diketahui bahwa port 525 rentan terhadap serangan [2].

Babys, Kusrini, dan Sudarmawan membahas tentang Analisis Aspek Keamanan Informasi Jaringan Komputer (Studi Kasus: STIMIK Kupang). Penelitian ini melakukan analisis terhadap aspek confidentiality yang merupakan salah satu aspek dari keamanan informasi. Analisis dilakukan dengan melakukan scanning menggunakan Zenmap pada setiap client dalam jaringan. Hasil scanning menemukan port 139 dan 445 terbuka. Berdasarkan hasil scanning dilakukan eksploitasi dengan memanfaatkan kelemahan pada port 445 . Hasil dari penelitian ini adalah ditemukannya kelemahan keamanan baik pada tools keamanan yang digunakan maupun kelemahan pada instalasi jaringan. Solusisolusi yang dihasilkan dalam penelitian ini adalah sebagai berikut: (1) Melakukan segmentasi pada jaringan menggunakan VLAN dengan metode Access Control Lists (ACL) dan Port Security; (2) Melakukan instalasi firewall disetiap client/host dalam jaringan untuk melindungi setiap port yang terbuka pada sistem operasi yang digunakan, dalam penelitian ini menunjukan bahwa aplikasi McAfee 8.8 mampu melindungi port yang terbuka [1].

\section{HASIL DAN PEMBAHASAN}

Penelitian ini dilakukan di kampus STIMIK Kupang. Tahap pertama dalam penelitian adalah tahap information gathering, pada tahap ini dilakukan proses scanning terhadap 378 IP address yang dialokasikan pada jaringan wifi yang digunakan bersama oleh Mahasiswa/I, dan jaringan wifi yang digunakan bersama oleh Dosen dan Pegawai. Proses scanning pada tahap ini bertujuan untuk mencari IP address dengan status open port. Hasil dari scanning yang dilakukan dapat dilihat pada tabel 1 berikut ini.

Tabel 1. Daftar ip address dengan status open port

\begin{tabular}{lll}
\hline No & \multicolumn{1}{c}{ IP address } & \multicolumn{1}{c}{ Open port } \\
\hline 1 & $10.10 .16 .36 / 26$ & 80,8080 \\
2 & $10.10 .16 .42 / 26$ & $80,135,139,445,8080$ \\
3 & $10.10 .16 .44 / 26$ & $80,135,139,445,5357$ \\
4 & $10.10 .16 .45 / 26$ & $80,135,139,445$ \\
5 & $192.168 .2 .2 / 26$ & $80,135,139,445,5357,49156$ \\
6 & $192.168 .2 .8 / 26$ & $80,135,139,445,1028$ \\
7 & $192.168 .2 .9 / 26$ & $80,135,139,445,49156$ \\
8 & $192.168 .2 .10 / 26$ & 80 \\
9 & $192.168 .2 .11 / 26$ & 80 \\
10 & $192.168 .2 .15 / 26$ & $80,135,139,445,49156$ \\
11 & $192.168 .2 .16 / 26$ & 80 \\
12 & $192.168 .2 .19 / 26$ & $80,135,139,445,7070$ \\
13 & $192.168 .2 .20 / 26$ & 80 \\
14 & $192.168 .2 .50 / 26$ & $80,135,139,445,49156$ \\
15 & $192.168 .2 .51 / 26$ & $80,135,443,445,5357$ \\
16 & $192.168 .2 .55 / 26$ & $80,135,139,443,445,3306$ \\
17 & $192.168 .2 .56 / 26$ & 80,6646 \\
18 & $192.168 .3 .13 / 24$ & $80,135,139,445,49152,49153,49154,49155$ \\
19 & $192.168 .3 .55 / 24$ & $80,135,139,445,1028$ \\
20 & $192.168 .3 .92 / 24$ & $80,135,443,445,5357$ \\
21 & $192.168 .3 .93 / 24$ & 80 \\
22 & $192.168 .3 .95 / 24$ & 80 \\
23 & $192.168 .3 .96 / 24$ & 80 \\
24 & $192.168 .3 .100 / 24$ & 80,49156 \\
25 & $192.168 .3 .151 / 24$ & $135,139,445$ \\
26 & $192.168 .3 .200 / 24$ & $80,135,139,445$ \\
\hline & &
\end{tabular}


Berdasarkan hasil scanning pada tabel 1 terdapat 26 IP address aktif berstatus open port dari 378 IP address yang dialokasikan. Pada penelitian ini terdapat juga beberapa IP address yang tidak terdeteksi hasil scanning, hal ini dikarenakan IP address tersebut dilindungi oleh personal firewall. Berikut merupakan informasi mengenai port yang ditemukan dari hasil scanning menggunakan Zenmap.

Tabel 2. Daftar port hasil scanning

\begin{tabular}{|c|c|c|c|c|}
\hline No & Port & State & Service & Version \\
\hline \multirow[t]{8}{*}{1} & $80 /$ tcp & Open & Tcpwrapped & - \\
\hline & & & http & $\begin{array}{lcc}\text { Apache httpd } & 2.2 .21 \quad((\text { Win32) } & \text { mod_ssl/2.2.21 } \\
\text { OpenSSL/1.0.0e } & P H P / 5.3 .8 & \text { mod_perl/2.0.4 } \\
\text { Perl/v5.10.1) } & & \end{array}$ \\
\hline & & & http & Apache httpd 2.2.14 ((Win32) DAV/2 \\
\hline & & & & mod_ssl/2.2.14 OpenSSL/0.9.8l \\
\hline & & & & mod_autoindex_color PHP/5.3.1 mod_apreq2- \\
\hline & & & & 20090110/2.7.1 mod_perl/2.0.4 Perl/v5.10.1) \\
\hline & & & http & TP-LINK WA901ND WAP http config \\
\hline & & & http? & - \\
\hline \multirow[t]{2}{*}{2} & $8080 /$ tcp & Open & http-proxy? & - \\
\hline & & & http & Apache httpd 2.4.6 ((Win32) PHP/5.4.17) \\
\hline 3 & 135/tcp & Open & Msrpc & Microsoft Windows RPC \\
\hline 4 & 139/tcp & Open & Netbios-ssn & Microsoft Windows netbios-ssn \\
\hline \multirow[t]{2}{*}{5} & 445/tcp & Open & Microsoft-ds & $\begin{array}{l}\text { Microsoft Windows } 7-10 \quad \text { microsoft-ds } \\
\text { (workgroup: WORKGROUP) }\end{array}$ \\
\hline & & & Microsoft-ds? & - \\
\hline 6 & $1028 / \mathrm{tcp}$ & Open & Unknown & - \\
\hline 7 & 49156/tcp & Open & Unknown & - \\
\hline 8 & 49152/tcp & Open & Unknown & - \\
\hline 9 & 49153/tcp & Open & Unknown & - \\
\hline 10 & 49154/tcp & Open & Unknown & - \\
\hline 11 & 49155/tcp & Open & Unknown & - \\
\hline 12 & $5357 / \mathrm{tcp}$ & Open & http & Microsoft HTTPAPI httpd 2.0 (SSDP/UpnP) \\
\hline 13 & 1028/tcp & Open & Unknown & - \\
\hline 14 & $7070 /$ tcp & Open & Ssl/realserver? & - \\
\hline \multirow[t]{2}{*}{15} & 443/tcp & Open & Ssl/http & Apache httpd 2.2.14 ((Win32) DAV/2 \\
\hline & & & & $\begin{array}{lr}\text { mod_ssl/2.2.14 } & \text { OpenSSL/0.9.8l } \\
\text { mod_autoindex_color } & \text { PHP/5.3.1 } \text { mod_apreq2- } \\
\text { 20090110/2.7.1 mod_perl/2.0.4 Perl/v5.10.1) }\end{array}$ \\
\hline 16 & 3306/tcp & Open & Mysql & MySQL (unauthorized) \\
\hline 17 & 6646 & open & Tcpwrapped & - \\
\hline 18 & $513 /$ tcp & Closed & Login & - \\
\hline 19 & 2000/tcp & Closed & Cisco-sccp & - \\
\hline
\end{tabular}

Berdasarkan hasil scanning menggunakan Zenmap yang ditunjukan pada tabel 2 terdapat total 19 port. Dari 19 port tersebut terdapat 17 port dengan status open port dan 2 port dengan status closed port. Tahap berikut dalam penelitian ini adalah finding vulnerability menggunakan nmap untuk mengetahui potential vulnerability. Berdasarkan hasil scanning menggunakan nmap terdapat potential vulnerability seperti yang ditunjukan pada gambar 2 dan gambar 4. 


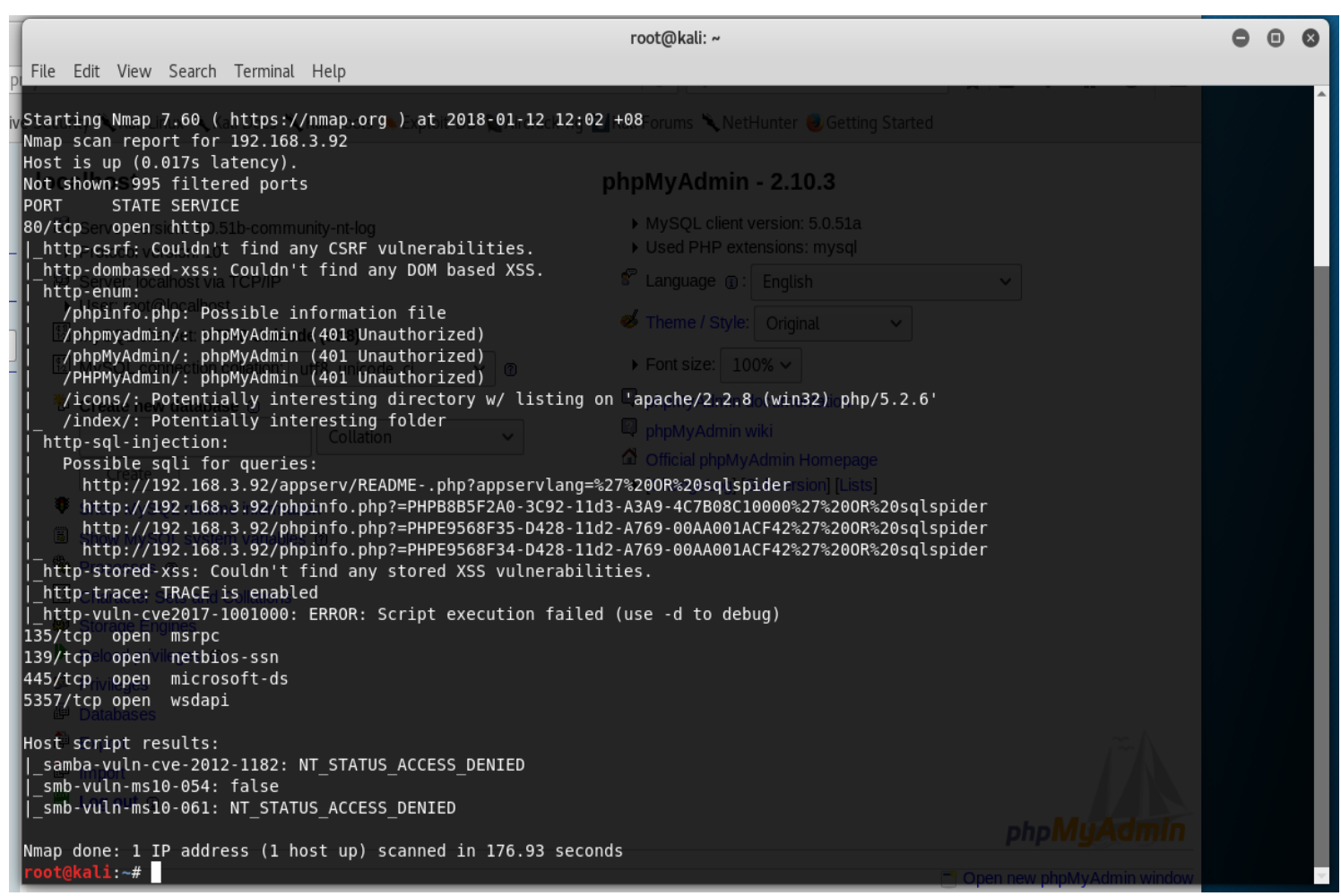

\section{Gambar 2. Potential Vulnerability Pada Port 80}

Pada gambar 2 menunjukan potential vulnerability di port 80 pada user dengan IP 192.168.3.92/24. Vulnerability ini dikarenakan terbukanya akses aplikasi phpmyadmin ke publik, seharusnya aplikasi phpmyadmin tidak dibuka aksesnya ke publik. Vulnerability ini berhasil di eksploitasi, ini ditunjukan pada gambar 3 dimana attacker berhasil login ke aplikasi phpmyadmin. hal ini tentunya beresiko terhadap keamanan data apabila didalam aplikasi phpmyadmin tersebut tersimpan database yang sifatnya penting.

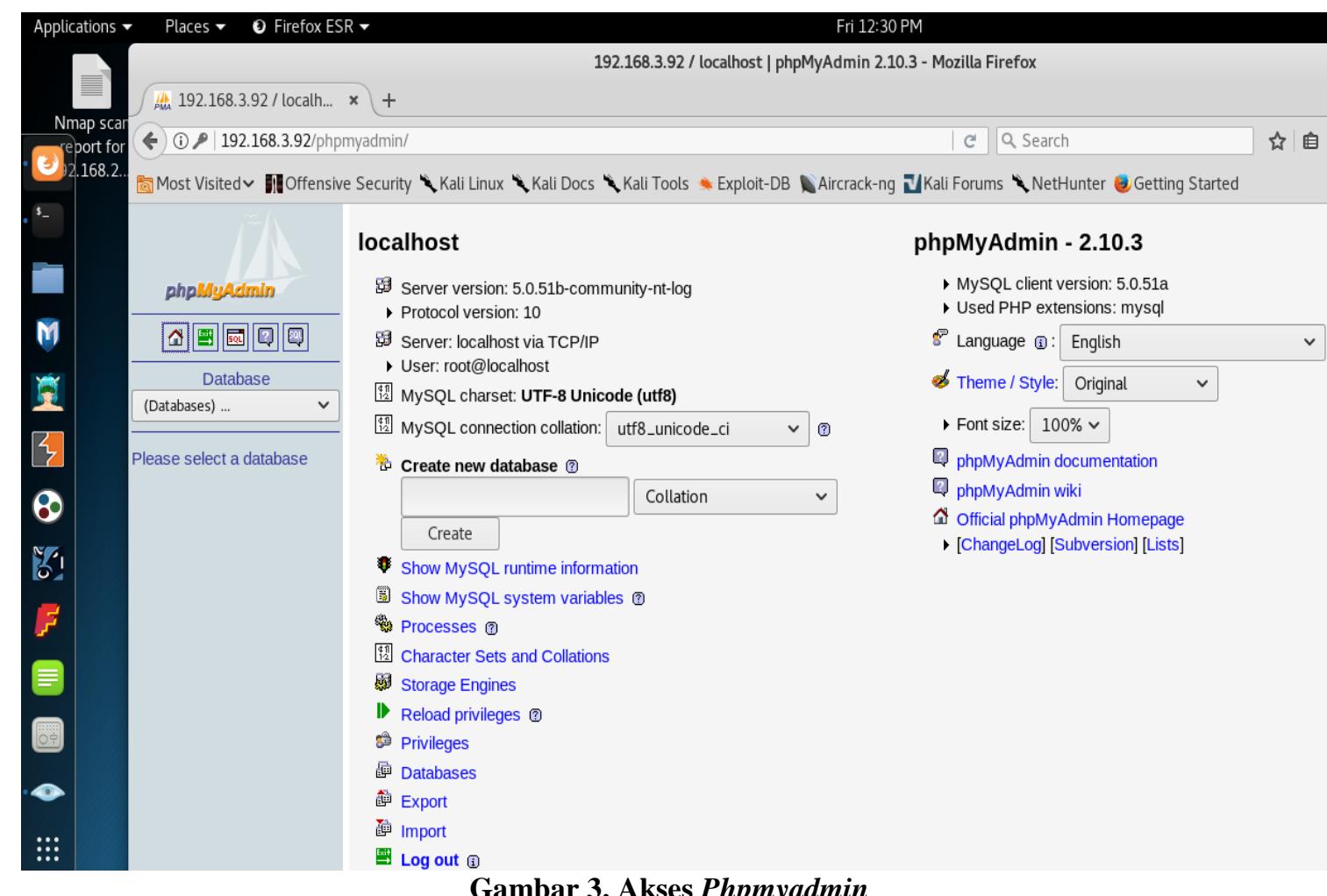


Vulnerable port yang ditemukan berikutnya adalah pada port 445 milik user dengan IP 192.168.2.8/26, dapat dilihat pada gambar 4. Port 445 merupakan vulnerable port yang sebelumnya telah dimanfaatkan oleh crypto-ransomware WannaCry untuk menyebar [6]. Vulnerability ini terjadi karena user belum melakukan update pada sistem operasi Windows yang digunakan. Seperti diketahui bahwa Microsoft telah mengeluarkan update untuk mengamankan vulnerability pada port 445 . Oleh karena itu, user disarankan untuk melakukan update secara periodik [7].

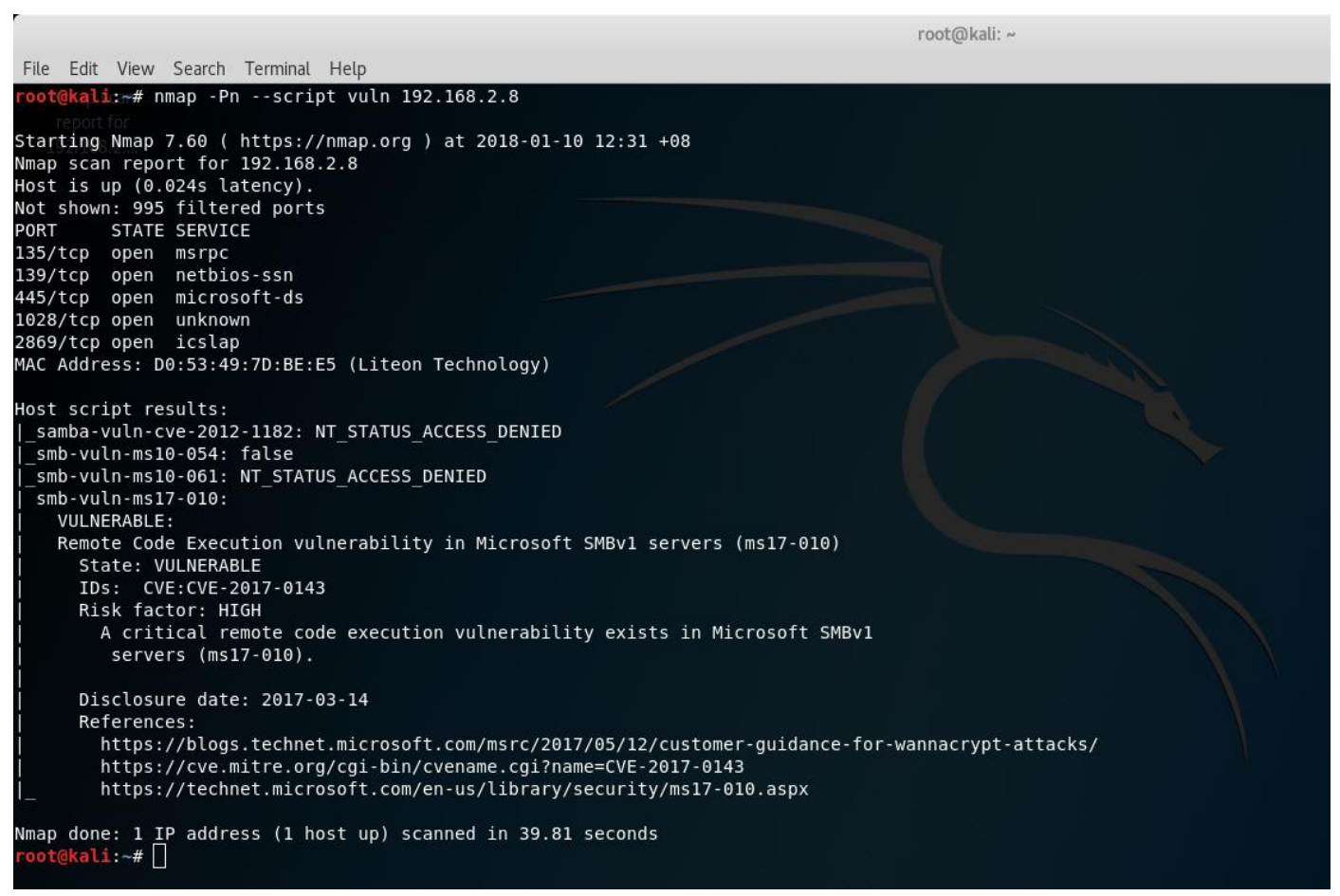

\section{Gambar 4. Potential Vulnerability Pada Port 445}

Pada gambar 5 berikut menunjukan port 445 pada user dengan IP 192.168.2.8/26 berhasil di eksploitasi. Terbukanya port 445 dikarenakan pengguna mengaktifkan fungsi file-sharing pada sistem operasi Microsoft Windows. Oleh karena itu, disarankan apabila pengguna tidak melakukan aktifitas filesharing dalam jaringan publik wifi maka fungsi ini baiknya dinonaktifkan.

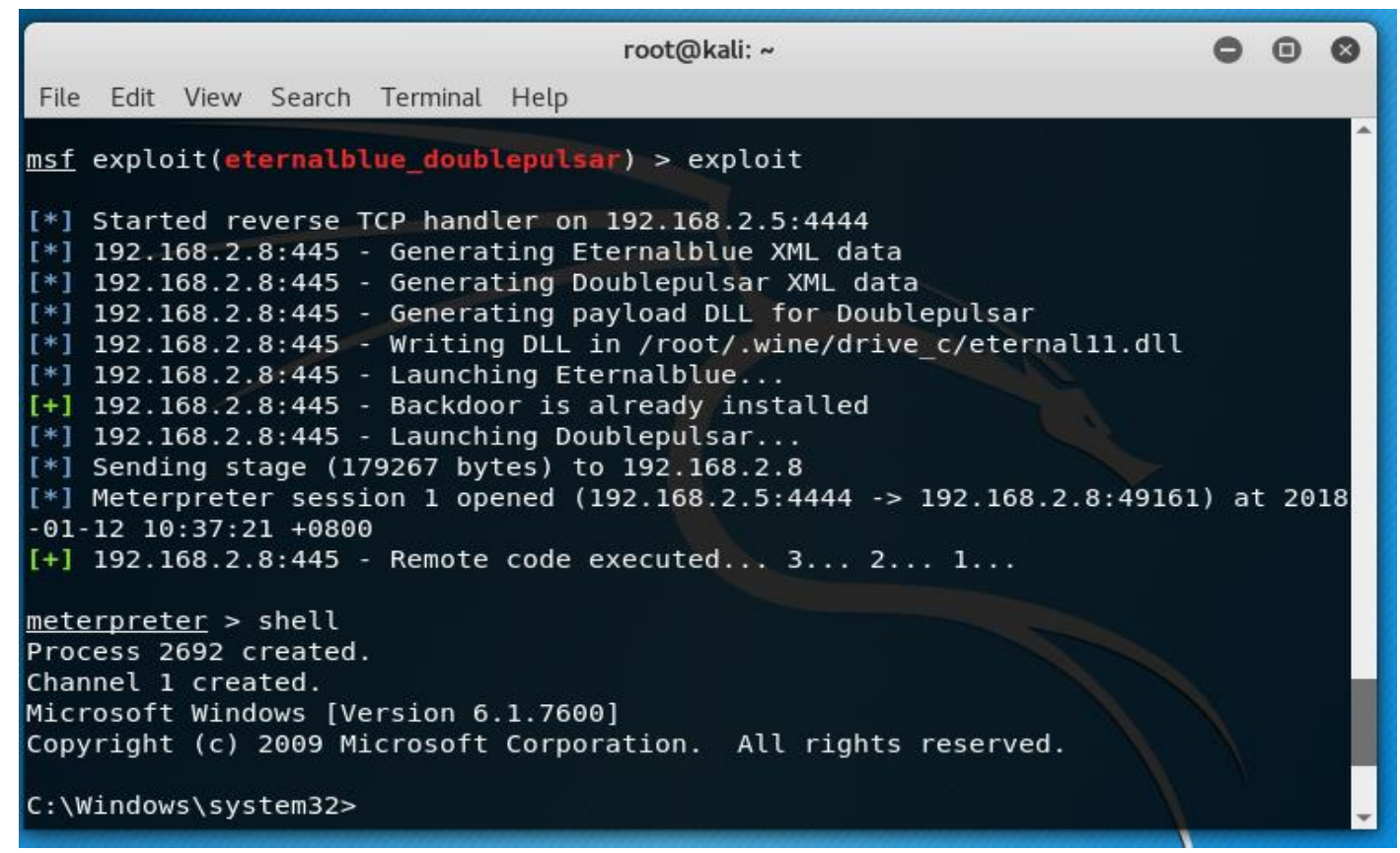

Gambar 5. Exploit Vulnerability Pada Port 445 
Dari hasil eksploitasi yang dilakukan dalam penelitian ini ditemukan 2 vulnerable port yaitu, port 80 dan port 445. Fungsi dari masing-masing port dapat dilihat pada tabel 3 berikut.

Tabel 3. Daftar vulnerable port

\begin{tabular}{lcccl}
\hline No & Port & State & Service & \multicolumn{2}{c}{ Fungsi } \\
\hline 1 & $80 /$ tcp & Open & http? & $\begin{array}{l}\text { Digunakan oleh aplikasi phpmyadmin untuk } \\
\text { administrasi database }\end{array}$ \\
2 & $445 / \mathrm{tcp}$ & Open & Microsoft-ds & $\begin{array}{l}\text { Digunakan oleh SMB untuk file-sharing dalam } \\
\text { jaringan }\end{array}$ \\
\hline
\end{tabular}

\section{KESIMPULAN}

Penggunaan publik wifi penuh dengan resiko keamanan, hal ini dikarenakan publik wifi biasanya memiliki banyak pengguna dengan banyak motivasi yang tidak diketahui. Oleh karena itu, perlu kesadaran dari pengguna publik wifi mengenai keamanan sehingga bisa berinternet secara aman dan terhindar dari tindakan eksploitasi yang memanfaatkan vulnerable port. Berdasarkan pengujian yang telah dilakukan disimpulkan bahwa terdapat beberapa hal yang bisa dilakukan untuk menghindarkan pengguna publik wifi dari tindakan eksploitasi yang memanfaatkan vulnerable port.

a. Melakukan update secara periodik baik pada sistem operasi yang digunakan maupun pada aplikasi yang digunakan.

b. Menggunakan personal firewall yang dapat melindungi setiap port yang terbuka.

c. Pada waktu mengakses publik wifi pengguna diharapkan menutup aplikasi-aplikasi yang tidak diperlukan yang dapat menyebabkan terbukanya port.

d. Pada waktu mengakses publik wifi, untuk pengguna sistem operasi Windows diharapkan menonaktifkan fitur file and printer sharing dan juga menonaktifkan fitur network discovery.

Untuk penelitian selanjutnya diharapkan dapat dikembangkan suatu sistem pada jaringan publik wifi yang berfungsi sebagai network firewall yang dapat melindungi setiap client yang terhubung dari tindakan eksploitasi yang memanfaatkan vulnerable port.

\section{DAFTAR PUSTAKA}

[1] Babys, Jemi Yohanis., Kusrini. and Sudarmawan., 2013. “ANALISIS ASPEK KEAMANAN INFORMASI JARINGAN KOMPUTER (Studi Kasus: STIMIK Kupang)". Seminar Nasional Informatika 2013 (semnasIF 2013) UPN ”Veteran” Yogyakarta, ISSN: 1979-2328, E-7 - E14.

[2] Lee, S., Im, S.Y., Shin, S.H., Roh, B.H. and Lee, C., 2016. Implementation and vulnerability test of stealth port scanning attacks using ZMap of censys engine. Information and Communication Technology Convergence (ICTC) International Conference, pp. 681-683.

[3] Navamani, B.A., Yue, C. and Zhou, X., 2017. An Analysis of Open Ports and Port Pairs in EC2 Instances. IEEE 10th International Conference, pp.790-793.

[4] Pawar, M.V. and Anuradha, J. 2015. Network security and types of attacks in network. Procedia Computer Science, 48, pp.503-506.

[5] Symantec employee. The risks of public Wi-Fi, https://us.norton.com/internetsecurity-privacy-risksof-public-wi-fi.html, diakses jam 08.38 WITA tanggal 20 Februari 2018.

[6] The European Union Agency for Network and Information Security (ENISA). WannaCry Ransomware Outburst, https://www.enisa.europa.eu/publications/info-notes/wannacry-ransomwareoutburst, diakses jam 08.40 WITA tanggal 20 Februari 2018.

[7] The Microsoft Security Response Center. Customer Guidance for WannaCrypt attacks, https://blogs.technet.microsoft.com/msrc/2017/05/12/customer-guidance-for-wannacrypt-attacks/, diakses jam 08.34 WITA tanggal 20 Februari 2018. 
Jurnal SIMETRIS, Vol. 9 No. 1 April 2018

ISSN: 2252-4983

[8] Weidman, Georgia. (2014). Penetration testing: A Hands-On Introduction to Hacking. San Francisco: No Starch Press, Inc. 